Sharif University of Technology
Scientia Iranica
Transactions E: Industrial Engineering
hCIENTIA

\title{
Robust and sustainable full-shipload routing and scheduling problem considering variable speed: A real case study
}

\author{
M. Rabbani ${ }^{a, *}$, S. Sadeghsa ${ }^{a}$, M. Vaez-Alaei ${ }^{a}$, and H. Farrokhi-Asl ${ }^{\text {b }}$ \\ a. School of Industrial Engineering, College of Engineering, University of Tehran, Tehran, Iran. \\ b. School of Industrial Engineering, Iran University of Science \& Technology, Tehran, Iran.
}

Received 1 September 2017; received in revised form 26 January 2018; accepted 9 June 2018

\author{
KEYWORDS \\ Maritime \\ transportation; \\ Speed optimization; \\ Carbon emission; \\ Sustainability; \\ Fuzzy; \\ Robust optimization.
}

\begin{abstract}
This paper presents a sustainable multi-objective routing and scheduling problem for maritime transportation considering ship's variable speeds under uncertainty. The proposed model is aimed at satisfying three separate dimensions of sustainability including economic, environmental, and social simultaneously while finding the best routes and schedule for each ship. The first objective is aimed at meeting economic goals by minimizing shipping cost. The second objective concerns the social dimension of sustainability by maximizing job creation and opportunities with respect to the number of intransitive workers in ships and ports. The third one concerns the minimization of $\mathrm{CO}_{2}$ emission to address the environmental issue. Several test problems are applied to validate the proposed model, and sensitivity analysis is used to demonstrate the effects of the model's parameters on the objective function value. Augmented $\varepsilon$-constraint is implemented as a solution method to solve the multi-objective mathematical model. This is the first ship routing and scheduling paper, and it has considered three aspects of sustainability under uncertainty solved by augmented $\varepsilon$-constraint. To solve the large-sized model, factual input data from a real case study are considered. Computational results show significant positive managerial effects.
\end{abstract}

(C) 2019 Sharif University of Technology. All rights reserved.

\section{Introduction}

Maritime transportation is one of the most popular and beneficial modes among different types of transportation modes in global trade for so many reasons. For example, it is an economical way of transportation for most of the shipments and related industries; maritime

\footnotetext{
*. Corresponding author. Tel.: +9821-88021067;

Fax: +9821-88013102

E-mail addresses: mrabani@ut.ac.ir (M. Rabbani);

shohre.sadeghsa@ut.ac.ir (S. Sadeghsa);

Maliheh.v.alaei@ut.ac.ir (M.Vaez-Alaei);

hamed.farrokhi@ut.ac.ir (H.Farrokhi-Asl)
}

doi: $10.24200 /$ sci.2018.5106.1100 transportation is the only way to transport huge or irregular shipment, etc. Ship transportation has highly increased recently as a result of globalization [1]. According to recent reports, more than $80 \%$ of universal businesses and trades in terms of volume and about $70 \%$ of them in terms of value are performed through shipping, and these estimations are even higher in developing countries [2]. There are three kinds of ships for shipping cargoes in the literature: industrial, linear, and tramp [3]. Industrial cargo shipping is a kind of shipping in which the cargo owner plays the main role in transporting his own shipment in order to minimize the cost. Linear shipping is a kind of shipping in which travels are done in a fixed sequence frequently, and shipping companies announce these fixed routes. 
Tramp ships are like taxis; they head towards any port with available shipments. Unlike linear shipping, a ship is able to sail in different routes and with variable transportation speeds in tramp shipping in order to maximize benefits or minimize the cost.

Significant improvements in the shipping industry have raised the competitive field in the global economy. Ocean shipping is a kind of industry with high capitalization and considerable operation cost; thus, among these features, it is becoming critical to find ways to maximize the benefits of this industry such as changing fleet sizing, routing, scheduling, ship network design, etc. [4]. Moreover, due to the importance of the global environment and rapid turning of industries to green industries, some decision-makers and researchers are showing interest in sustainability and green approach in the shipping industry. One of the important concerns is emissions of greenhouse gasses in ship transportation, such as high $\mathrm{NO}_{x}$ and $\mathrm{CO}_{2}$ emission, which is a result of fuel consumption, with a lot of negative influence on climate and pollutions. According to reliable research studies and datasets, we have faced an $86 \%$ increase in $\mathrm{CO}_{2}$ emissions from the shipping industry in 2007 in comparison with 1990 . If no actions are taken, these emissions continue to rise by $150 \%-250 \%$ based on expectations [5].

One of the most important factors in controlling emissions of the ship along with fuel consumption and fuel cost is transportation speed. Many studies in the literature have considered the optimization rule of sailing speed in achieving more benefits with the highly green shipping industry. For instance, interested readers can refer to [6-8].

Generally, the total cost of ship transportation consists of transportation expenses, consumption expenses, operation expenses, depreciation, and so forth. In order to consider sustainability and, also, carbon emission in maritime transportation problems, it is necessary to integrate sustainability with shipping cost in a single model [9]. Integrating some of the decisions necessary to address sustainable factors was a critical topic for researchers in the last decades. Jansen [10] introduced three related decisions to develop sustainability: structure, culture, and technology. In 2008, Vachon and Mao [11] presented sustainability by integrating environmental and social factors. Cuček et al. [12] published a review paper on three dimensions of sustainability: social, environmental, and economic integration.

This paper aims to define a maritime routing and scheduling problem with respect to three dimensions of sustainability (see Figure 1):

1. Economic: To minimize costs in order to increase benefits by considering sailing cost, fuel cost, and revenue of sailing shipments;

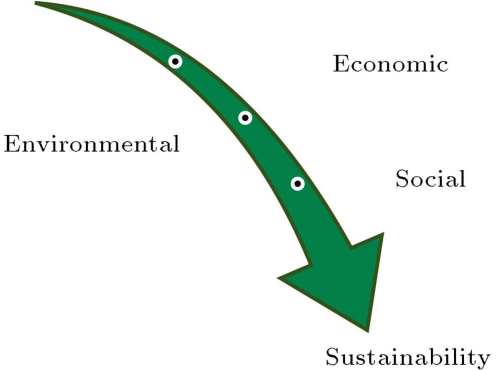

Figure 1. Schematic view of sustainability dimensions considered in this study.

2. Environment: To minimize the carbon emission of ships by determining proper route and speed of each ship;

3. Social: Every industry including the shipping industry has some social aspects.

In this study, job creation is considered as the social effect of maritime transportation followed by maximizing job opportunities belonging to a number of ships and ports. These three objectives are presented simultaneously to define the ship transportation problem. Fuzzy development and robust programming are considered for modeling required in this paper in order to make it closer to the real-world cases. To the best of our knowledge, this is the first ship routing and scheduling paper, which considers three aspects of sustainability and variable speed in a fuzzy concept.

The remainder of this paper is structured as in the following. Section 2 is dedicated to the literature review of different aspects of this paper. Section 3 concerns the description of the problem in order to explain the problem for a better understanding. Section 4 goes to mathematical modeling and explains notations and problem model in detail. The solution methodolgoy is presented in Section 5, and numerical results and case-study explanation are conducted in Sections 6 and 7, respectively. Managerial insights are shown in Section 8. Finally, concluding remarks and future research directions are provided in Section 9 .

\section{Literature review}

Maritime transportation problems, which form the background of this paper, can be divided into some categories. Some of these studies are mentioned in the following subsections.

\subsection{Routing and scheduling}

Maritime transportation routing and scheduling can be taken as a whole different subject because of how ships operate under various circumstances $[13,14]$. A review on ship routing and scheduling papers for investigation of theoretical and practical papers associated with this subject was published [15]. Brønmo et al. [16] 
proposed a shipping problem with time window and flexible cargo sizes and a partitioning approach as a methodology to solve this problem. Results indicated that using flexible cargo sizes had economical influence. Routing and scheduling for a fleet of ships and a single product was designed in order to minimize the cost of operations without any time out in ports [17]. A dynamic programming model was developed in routing and scheduling in liner shipping [18]. Bendall and Stent [19] presented a model to obtain an optimal number of vessels and fleets in shipping cargoes. In addition, Azaron and Kianfar [20] examined the climate ship routing problem. An ocean transportation inventory routing problem was considered for multiple products, and different sections were defined in ships for various products [21]. By proposing split loads, the restriction on carrying shipments with different ships was removed, and the ship routing and scheduling problem with split loads was examined by a neighborhood heuristic search [22]. Fagerholt et al. [23] introduced a methodology for strategic routing and scheduling for tramp and industrial ships. A routing and scheduling problem for split loads with time window was presented to maximize the benefit and minimize cost together [24]. A continuous and discrete time horizon for ship routing and scheduling with multiple products and different fuel consumptions in various ports as a mathematical model is shown in the related literature [25]. Moon et al. [26] resolved an integrated ship routing problem of fleet extensions with network design; for this NP-hard problem, a genetic algorithm was suggested.

\subsection{Environmental and social consideration}

Compared to other aspects of maritime transportation, carbon emission has received insignificant attention; hence, due to the importance of environmental issues noticeable these days, $\mathrm{CO}_{2}$ emission has managed to gain researchers' attention. Some of the related research studies on this subject are mentioned in this subsection.

Corbett and Koehler [27] introduced a method for manufacturing inventories, which are fuel based, and examined its role in ships' emissions. In order to maximize the profit of the shipping industry with an increase in fuel price, optimal speed will decrease; in addition, $\mathrm{CO}_{2}$ emissions of ships will reduce $[28,29]$. Eyring et al. [30] proposed an emission inventory for the global shipping industry. Endresen et al. [31] studied passengers and cargo ships emission. Corbett et al. [28] concluded that decreasing ships' speed could lead to the reduction of sailing emissions. Considering speed optimization and ships' emissions, Yin et al. [32] proposed a profit-maximizing model to investigate the relationship between slow steaming, fuel consumption, and environmental aspects. A real analysis was devel- oped to measure carbon emission effects [33]. De et al. [9] indicated a ship routing and scheduling problem for multiple products and various ports by considering $\mathrm{CO}_{2}$ emission and solved the meta-heuristic problem due to the complexity of the model.

One of the sustainability objectives is to consider social aspects; however, to the best of our knowledge, this is the first paper that considers the objective of evaluating and maximizing job creation in the shipping industry.

\subsection{Variable speeds and fuel consumption}

The speed of each transporting arc was presented as a decision variable in a tramp ship routing and scheduling problem with speed optimization. Two different algorithms were proposed to solve this problem, and computational results showed improvements in the tramp routing and scheduling problem by considering variable speeds [34]. The degree of the relationship between fuel consumption and ship's speed was illustrated in some papers [6,7]. Gatica and Miranda [35] suggested a full-shipload routing with speed optimization by applying discrete time windows. Wang and Meng [36] studied the sailing speed of ships for each shipping route in liner shipping; in the meantime, routing and transshipment were considered. Psaraftis and Kontovas [37] considered crucial elements in various speeds and optimizations of ships to find a proper result. In case of an increase in fuel costs, ships' speed should decrease in order to reduce costs and maximize benefits. A further decrease in speed reduces fuel emissions of ships [28]. The optimal route and speed are examined in ship routing problems in which routes, originations, and destinations are considered as fixed parameters [36]. A novel routing model was suggested for a real-world case study which was solved with a heuristic by considering speed optimization [38]. Wen et al. [8] applied routing and scheduling to full-shipload by considering variable speeds; their computational results showed that optimization of speeds is a practical way to increase the total income up to $16 \%$, and fuel cost is a critical factor in selecting a proper speed rate and obtaining the total profit.

\subsection{Uncertainty consideration}

Dubois et al. [39] indicated that uncertainty in mathematical problems could be divided in two groups:

- Uncertainty in input data;

- Flexibility in constraints or objectives.

The first group is the most common one in related literature, and stochastic programming is a useful method to deal with it. The second group is divided into two groups: flexibility in objectives as flexibility in target and flexibility in constraints as a soft limitation. Flexible mathematical programming is a well-known 
approach to coping with these kinds of flexibility in constraints or objectives [40,41].

Not all input parameters can be defined as exact parameters in real-world cases for so many reasons. First, some input data are innately accidental; second, lack of knowledge and poor datasets lead to stochastic programming $[40,42]$.

There are three principal approaches in the literature to deal with uncertainty in mathematical programming:

1. Stochastic programming;

2. Fuzzy programming;

3. Robust optimization.

According to problem structure, uncertainty type, and incompleteness in parameters, one of these approaches or a combination of some of them can be used in problems.

The investigation into the literature shows that there are studies on uncertainty in maritime transportation. For instance, readers are referenced to the following: container port problem by TOPSIS approach under fuzzy environment [43], a fuzzy genetic approach to ships routing [5], and robust ship routing problem [44] using multiple time windows in ship scheduling [45].

In this paper, according to a lack of reliable datasets, input parameters are not considered exactly herein, and some of the limitations are naturally flexible such as time windows; therefore, a mixed flexible-probabilistic robust programming is used to cope with uncertainty in the mathematical model [46]. Considering gaps in maritime transportation literature and to the best of our knowledge, this is the first sustainable ship routing and scheduling paper that considers variable speeds, fuel consumption, and robust-probabilistic formulation. Table 1 shows the proposed features compared with the closest studies in the literature.

\section{Problem description}

In this paper, a full-shipload problem is defined to transport shipments between different nods. The routing and scheduling problem determines the best feasible routes within a rational time to transport shipments from loading port to unloading port [8]. Objectives are defined to minimize total cost, to maximize social impact by creating jobs, and to minimize $\mathrm{CO}_{2}$ emission in order to protect the environment, simultaneously. In this problem, a shipping line transports liquid products. To transport liquid, tramp ships in the fullshipload mode are the most popular kind of transportation due to their features. Ships have different speed performances, fuel cost, $\mathrm{CO}_{2}$ emission, size, load capacity, number of personals, and cost parameters. A ship operator receives shipment orders from different pickup and delivery ports. Each order has its specific pickup and delivery ports with a specific time window when each ship must start to load shipments. The proposed model determines whether the operator accepts the order or not, which ship should pick up the order, and at what time/speed/route the ship should sail. A schematic view of this paper problem is shown in Figure 2.

To establish each industry, the most important question is how much the industry is beneficial; thus, finding an optimal solution for minimizing cost and maximizing benefit is the first step in evaluating this study problem. Ship cost, fuel cost, worker salary, and transportation incomes are considered to find the optimal routing and scheduling from an economic point of view.

Manpower plays a critical role in maritime transportation for both ships and ports. In this problem,

Table 1. Summary of related literature.

\begin{tabular}{|c|c|c|c|c|c|c|c|c|}
\hline Articles & Scheduling & Routing & $\begin{array}{c}\text { Tramp } \\
\text { ship }\end{array}$ & Speed & $\begin{array}{c}\text { Job } \\
\text { creation }\end{array}$ & $\begin{array}{l}\text { Fuel } \\
\text { cost }\end{array}$ & $\begin{array}{c}\text { Carbon } \\
\text { emission }\end{array}$ & $\begin{array}{c}\text { Fuzzy } \\
\text { formulation }\end{array}$ \\
\hline$[28]$ & & & & $\checkmark$ & & & $\checkmark$ & \\
\hline$[45]$ & $\checkmark$ & & & & & & & $\checkmark$ \\
\hline [23] & $\checkmark$ & $\checkmark$ & $\checkmark$ & & & & & \\
\hline$[47]$ & & $\checkmark$ & & & & & & $\checkmark$ \\
\hline$[35]$ & $\checkmark$ & $\checkmark$ & & $\checkmark$ & & & & \\
\hline$[24]$ & $\checkmark$ & $\checkmark$ & & & & & & \\
\hline$[25]$ & $\checkmark$ & $\checkmark$ & & & & $\checkmark$ & & \\
\hline$[32]$ & & & & $\checkmark$ & & $\checkmark$ & $\checkmark$ & \\
\hline$[9]$ & $\checkmark$ & $\checkmark$ & & $\checkmark$ & & $\checkmark$ & $\checkmark$ & \\
\hline$[8]$ & $\checkmark$ & $\checkmark$ & $\checkmark$ & $\checkmark$ & & $\checkmark$ & & \\
\hline This study & $\checkmark$ & $\checkmark$ & $\checkmark$ & $\checkmark$ & $\checkmark$ & $\checkmark$ & $\checkmark$ & $\checkmark$ \\
\hline
\end{tabular}




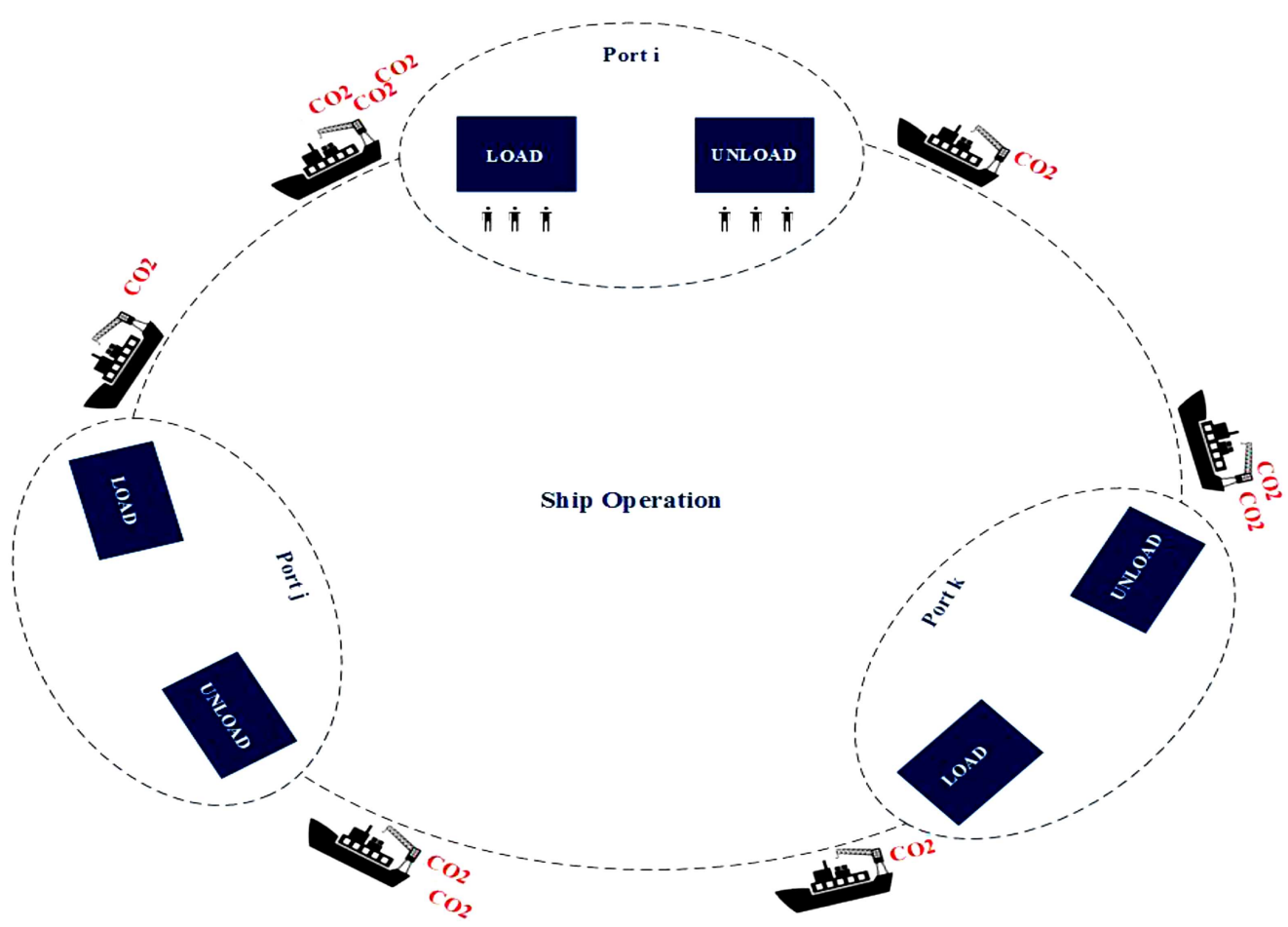

Figure 2. Three ports of the network between which ships travel.

according to the social aspect of sustainability objective, job creation of this routing and scheduling is to be maximized by considering workers in ships and nodes. Moreover, manpower cost is addressed as their salaries.

Ship's speed, fuel consumption, and emissions of greenhouse gasses are three different concepts in shipping which are closely related to each other. It is proven that ship emissions, such as $\mathrm{CO}_{2}$, can be reduced by determining an optimal speed [28,48]. It is required to consider that higher speed leads to higher fuel consumption and more emissions per traveling unit; however, it also leads to less transit time. Therefore, finding an optimal trade-off between these two factors is critical to satisfying both environmental and economic objectives of this paper.

Different ships have different origins and destination ports. The origin and destination are not predetermined for each ship. Ships have different speeds. They can pick shipments and transfer them to their destination at different speeds. High speeds save time, yet increase the cost and produce a greater amount of $\mathrm{CO}_{2}$. In addition to ship speed, fuel cost depends on which ship is loaded (laden) or sails empty (ballast).

Each node is considered as an individual port. Each port has different platforms for loading and unloading shipments. Ports can be represented as an origin or a destination of each ship or both of them. Each tramp ship should start its travel from its origin port and deliver as much shipment as it can collect from middle ports to its destination port. The port where a ship should end its journey is not predetermined. Dummy nodes are considered to achieve this aim. The model gives a sequence of ports with shipments to each ship. If the destination port of a shipment is not the origin port of the next shipment in a given sequence, the ship must travel empty. The model tries to minimize such empty trips. Each journey is followed by costs, yet with advantages.

Figure 2 shows a schematic view of the presented problem. This network with three ports shows a small sample for the problem. Ships travel between ports and emit $\mathrm{CO}_{2}$ in their route. The amount of their emission varies due to different speeds and fuel consumption. Ports and ships have a specific number of workers according to the port size and their amount of loading/unloading in ports and number of used ships.

\section{Mathematical formulation}

In this section, objectives, assumptions, notations, and mathematical model of this problem are presented. In addition, the mixed flexible-probabilistic robust programming is proposed at the end of this section.

\subsection{Objective functions}

The presented routing and scheduling problem is a multi-objective problem, which addresses three dimensions of sustainability simultaneously. The first objective function minimizes the total cost including the traveling cost of ships, fuel cost, ship cost, and 
workers' salary. In addition, the revenue for transporting shipments is considered. Since our problem involves full ship-load mode, the cost of fuel is equal to its maximum amount. Finally, cost of workers corresponds to the salary of workers in ships and workers in the port to transfer shipments in or out of the ship.

The second objective maximizes the total number of workers in order to create job opportunities and maximize social responsibility. Each ship has a defined number of workers, and ports require a number of workers.

Last but not least, the objective considers the environmental effects produced by ship transportations. The objective is realized by minimizing total $\mathrm{CO}_{2}$ emitted from ship trips and minimizing transport hazardous materials (i.e., gas and oil).

\subsection{Assumptions}

In order to present the mathematical modeling of the stated problem, some assumptions of this problem require to be clarified as follows:

- Our problem is not a complete graph, meaning that some ports cannot connect to each other directly. For example, it is not feasible to sail directly from port A to port B; some middle ports are necessary due to obstacles in a direct route or some available contracts; some routes are not feasible in the stated problem;

- An origin node could be a shipment node and, also, a destination node for different ships;

- It is not feasible for all ships to serve all shipments;

- Time window is only considered for pickup time (began of the service) for the shipments. In addition, it is determined by contracts;

- The benefits gained from serving each shipment are fixed, thus minimizing the total cost and maximizing the total benefit.

\subsection{Mathematical model}

The presented model in this paper is an extension to a routing and scheduling model, which has been published recently [8]. Only cost objective was considered in the previous study, while two other dimensions of sustainability, namely the environmental (concerning minimization of ships' $\mathrm{CO}_{2}$ emission) and the social (maximization of job creations), are proposed in this study. In addition, the fuzzy approach is formulated in order to cope with the lack of proper data, considering uncertainty in the model of this study.

All of sets, parameters, and decision variables used in the mathematical formulation are introduces in the following:

Sets: $N$ Set of all the nodes;
A

V

$S$

O

$D$

Parameters:

$l_{i}$

$\left[a_{i}, b_{i}\right]$

$d_{i j}$

$b_{i}^{v}$

$g_{v}$

$c_{s}^{v}$

$p_{i}$

$f_{\text {is }}$

$n_{s}$

$\mathrm{CO}_{2 s v}$

$h_{i}$

$w s_{s}$

$M_{s}$

$e_{i s}^{v}$

Variables:

$t_{i s}$

$x_{i j s}$

\section{Binary variables}

$z_{i j s}^{v} \quad 1$ if ship $s$ sails from shipment node

$i$ to shipment node $j$ at speed $v, 0$ otherwise;

$w_{i s}^{v} \quad 1$ if $\operatorname{ship} s$ serves shipment $i$ at speed $v, 0$ otherwise.

Distance between load and unload ports;

Time window;

Distance between two nodes $i$ and $j$;

Income of serve shipment $i$ by ship $s$ at speed $v$;

Time of traveling one distance unit at speed $v \in V$;

Fuel cost of ship $s$ traveling one distance unit at speed $v$;

Port service time;

1 is feasible for ship $s$ to serve shipment $i, 0$ otherwise;

Number of available ship $s$;

$\mathrm{CO}_{2}$ emission from ship $s$ with speed $v$;

Risk of serving hazardous material;

Number of personals working on each ship $s$;

Amount of payment for each person working on each ship $s$;

Cost of accepting shipment $i$ to serve with ship s at speed $v$ (including tax and personnel payments);

Time when ship $s$ starts loading shipment $i$;

Time span of ship $s$ arriving at the loading port of shipment $i$ to that arriving at the loading port of shipment $j$;

Objective functions and constraints are presented 
as follows:

$$
\begin{gathered}
\min \sum_{(i, j) \in A} \sum_{s \in S} \sum_{v \in V} c_{s}^{v} d_{i j} z_{i j s}^{v}+\sum_{i \in N} \sum_{s \in S} \sum_{v \in V} e_{i s}^{v} w_{i s}^{v} \\
-\sum_{i \in N} \sum_{s \in S} \sum_{v \in V} b_{i}^{v} w_{i s}^{v},
\end{gathered}
$$

$\max \sum_{i \in N} \sum_{s \in S} \sum_{v \in V} w_{i s}^{v}\left(n_{s}+w s_{s}\right)$

$$
+\sum_{i \in N} \sum_{s \in S} \sum_{v \in V} w s_{s} z_{i j s}^{v}
$$

$\min \sum_{(i, j) \in A} \sum_{s \in S} \sum_{v \in V} z_{i j s}^{v} \mathrm{CO}_{2_{s v}} d_{i j}$

$$
+\sum_{i \in N} \sum_{s \in S} \sum_{v \in V} w_{i s}^{v} h_{i}
$$

subject to:

$$
\begin{aligned}
& \sum_{j \in N} \sum_{s \in S} \sum_{v \in V} z_{i j s}^{v} \leq 1 \quad \forall i \in N_{0}, \\
& \sum_{j \in N} z_{o(s) j s}^{v}=n_{s} \quad \forall s \in S \\
& \sum_{j \in N} \sum_{v \in V} z_{i j s}^{v}-\sum_{j \in N} \sum_{v \in V} z_{j i s}^{v}=0 \quad \forall i \in N, \quad s \in S, \\
& \sum_{j \in N} \sum_{v \in V} z_{j d(s) s}^{v}=1 \quad \forall s \in S, \\
& p_{i}+\sum_{v \in V} l_{i} g_{v} w_{i s}^{v}+\sum_{v \in V} d_{i j} g_{v} z_{i j s}^{v}=x_{i j s} \\
& \forall(i, j) \in A, s \in S, \\
& t_{i s}+x_{i j s}-M\left(1-\sum_{v \in V} z_{i j s}^{v}\right) \leq t_{j s} \\
& \forall(i, j) \in A, \quad s \in S, \\
& a_{i} \leq t_{i s} \leq b_{i} \quad \forall i \in N, \quad s \in S, \\
& \sum_{v \in V} w_{i s}^{v} \leq f_{i s} \quad \forall i \in N_{0}, \quad s \in S, \\
& \sum_{j \in N_{i}^{+}} \sum_{v \in V} z_{i j s}^{v}=\sum_{v \in V} w_{i s}^{v} \quad \forall i \in N_{0}, \quad s \in S, \\
& z_{i j s}^{v}, w_{i s}^{v} \in\{0,1\} \quad \forall i, j \in N, \quad v \in V, \quad s \in S, \\
& t_{i s} \geq 0 \quad \forall i, j \in N, \quad s \in S, \\
& x_{i j s} \geq 0 \quad \forall i, j \in N, \quad s \in S .
\end{aligned}
$$

Objective function (1) aims to minimize the total transportation costs and maximize the total benefit from shipping the shipments, simultaneously. Objective function (2) considers the social dimension of ship transportation by maximizing the number of workers working in each cargo-ship. Objective function (3) minimizes total $\mathrm{CO}_{2}$ emissions in total trips. Eq. (4) guarantees that each shipment is served by at most one ship. Eq. (5) ensures that all ships leave the origin port. Eq. (6) forces the ships to leave the ports until the end of the trip. Eq. (7) ensures that each ship finishes the trip at its destination. Eq. (8) calculates the total time span. If $x_{i j s}^{v}=1$, Eq. (9) calculates the time span of ships that arrive at the loading port of shipment $i$ to those arriving at the loading port of shipment $j$. $M$ represents a large number. Eq. (10) calculates the time window. If a shipment is served by a ship, it can only be transported at a specific speed (Eq. (11)). Eq. (12) ensures the balance between $x_{i j s}^{v}$ and $y_{i s}^{v}$. Eqs. (13)-(15) represent the binary and nonnegative variables.

\section{A mixed probabilistic-flexible formulation}

In the real world, some required data are unclear and vague; thus, they are assumed fuzzy in nature. The triangular fuzzy numbers are commonly used for modeling such imprecise parameters. The possibility distribution of the parameters is represented in Figure 3. The imprecise parameters are described in Table 2.

$\mathrm{CO}_{2}$ emission rate is a fuzzy parameter because data for this parameter are considered optimistically. Therefore, it can increase or decrease by overflow or underflow loading. A port service time strongly depends on the number of personnel and their ability. It is not fixed due to some reasons such as shift changing or hourly workers. The time of traveling one distance unit at speed $v \in V$ is not a fixed parameter due to some unpredictable variables such as climate change, sudden problems on the sea, or ETC. As such, in the model formulation, Constraint (10) needs to be flexible, and violation of the time window must have a

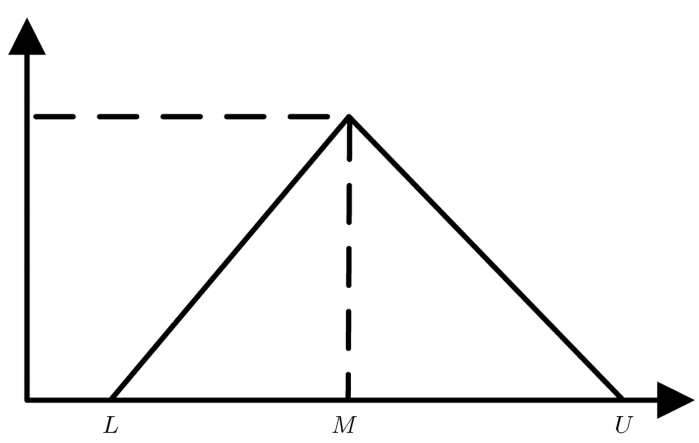

Figure 3. Triangular possibility distribution of parameters generated to solve a sample problem. 
Table 2. The imprecise parameters.

\begin{tabular}{lll}
\hline$g_{v}$ & The time of traveling one distance unit at speed $v \in V$ & $\left(g_{v 1}, g_{v 2}, g_{v 3}\right)$ \\
$p_{i}$ & A port service time & $\left(p_{i 1}, p_{i 2}, p_{i 3}\right)$ \\
$\mathrm{CO}_{2 s v}$ & $\mathrm{CO}_{2}$ emission from each ship with each speed & $\left(\mathrm{CO}_{2_{s v 1}}, \mathrm{CO}_{2_{s v 2}}, \mathrm{CO}_{2_{s v 3}}\right)$ \\
\hline
\end{tabular}

penalty cost. Therefore, it is written as Eq. (16):

$$
a_{i} \widetilde{\leq} t_{i s} \widetilde{\widetilde{\leq}} b_{i} \quad \forall i \in N, \quad s \in S
$$

The fuzzy form of the model formulation is as follows:

$$
\begin{array}{r}
\min \sum_{(i, j) \in A} \sum_{s \in S} \sum_{v \in V} z_{i j s}^{v} \widehat{\mathrm{CO}_{2 s v}} d_{i j} \\
+\sum_{i \in N} \sum_{s \in S} \sum_{v \in V} w_{i s}^{v} h_{i},
\end{array}
$$

subject to:

$$
\begin{aligned}
& \tilde{p}_{i}+\sum_{v \in V} l_{i} \widetilde{g_{v}} w_{i s}^{v}+\sum_{v \in V} d_{i j} \widetilde{g_{v}} z_{i j s}^{v}=x_{i j s} \\
& \forall(i, j) \in A, \quad s \in S, \\
& a_{i} \widetilde{x}_{i s} \quad \forall i \in N, \quad s \in S, \\
& t_{i s} \underset{\leq}{\leq} b_{i} \quad \forall i \in N, \quad s \in S,
\end{aligned}
$$

and Constraints (1), (4)-(7), and (9)-(15).

\subsection{Crisp equivalent of the formulation}

Robust fuzzy mathematical programming methods are discussed widely as in [46]; therefore, the suggested robust programming method was used in [49]. The proposed mixed probabilistic-flexible formulation is formulated as follows:

$$
\begin{aligned}
\min & \sum_{(i, j) \in A} \sum_{s \in S} \sum_{v \in V} z_{i j s}^{v} \\
& \left(\frac{\mathrm{CO}_{2_{s v 1}}+4 \mathrm{CO}_{2_{s v 2}}+\mathrm{CO}_{2_{s v 3}}}{6}\right) d_{i j} \\
& +\sum_{i \in N} \sum_{s \in S} \sum_{v \in V} w_{i s}^{v} h_{i}, \\
& {\left[\left(\sum_{(i, j) \in A} \sum_{s \in S} \sum_{v \in V} z_{i j s}^{v} \mathrm{CO}_{2_{s v 3}} d_{i j}\right)\right.} \\
& \sum_{(i, j) \in A} \sum_{s \in S} z_{i j s}^{v} \\
& {\left.\left[\frac{\mathrm{CO}_{2_{s v 1}}+4 \mathrm{CO}_{2_{s v 2}}+\mathrm{CO}_{2_{s v 3}}}{6}\right) d_{i j}\right] }
\end{aligned}
$$

$$
\begin{aligned}
& +\omega\left[\left(t_{2}+\frac{t_{1}+t_{3}}{3}\right)(1-\alpha)\right] \\
& +\beta\left[\left(r_{2}+\frac{r_{1}+r_{3}}{3}\right)(1-\varepsilon)\right],
\end{aligned}
$$

subject to:

$$
\begin{aligned}
& \frac{\left(p_{i 1}+4 p_{i 2}+p_{i 3}\right)}{6}+\sum_{v \in V} l_{i} \frac{\left(g_{v 1}+4 g_{v 2}+g_{v 3}\right)}{6} w_{i} s^{v} \\
& \quad+\sum_{v \in V} d_{i j} \frac{\left(g_{v 1}+4 g_{v 2}+g_{v 3}\right)}{6} z_{i j s}^{v}=x_{i j s} \\
& \forall(i, j) \in A, \quad s \in S \\
& t_{i s} \geq a_{i}-\left(t_{2}+\frac{t_{1}+t_{3}}{3}\right)(1-\alpha) \\
& \forall i \in N, \quad s \in S, \\
& t_{i s} \leq b_{i}+\left(r_{2}+\frac{r_{1}+r_{3}}{3}\right)(1-\varepsilon) \\
& \forall i \in N, \quad s \in S, \\
& 0 \leq \varepsilon, \quad \alpha \leq 1,
\end{aligned}
$$

and Constraints (4)-(7), and (9)-(15).

The first two terms of objective function (20) are associated with $\mathrm{CO}_{2}$ emissions, which are crisped by the average of $\mathrm{CO}_{2}$. The other terms calculate the total penalty cost of possible violation of the soft constraints. The penalty costs are considered for violation of the time window via parameters $\omega$ and $\beta$ in the proposed model. Notice that $\alpha$ and $\varepsilon$ are the satisfaction levels, and the model optimizes these variables.

\section{Solution methodology}

In this section, the methodology to solve the presented problem is demonstrated. Figure 4 describes this paper framework as a flowchart. The proposed formulation contains three separate objective functions. We solve our formulation with these three objectives separately, and obtained results show the conflict between objectives, as described in Figures 5-7. Therefore, in this problem, there is no single optimal solution, and Pareto-optimal solutions (a set of efficient solutions) 


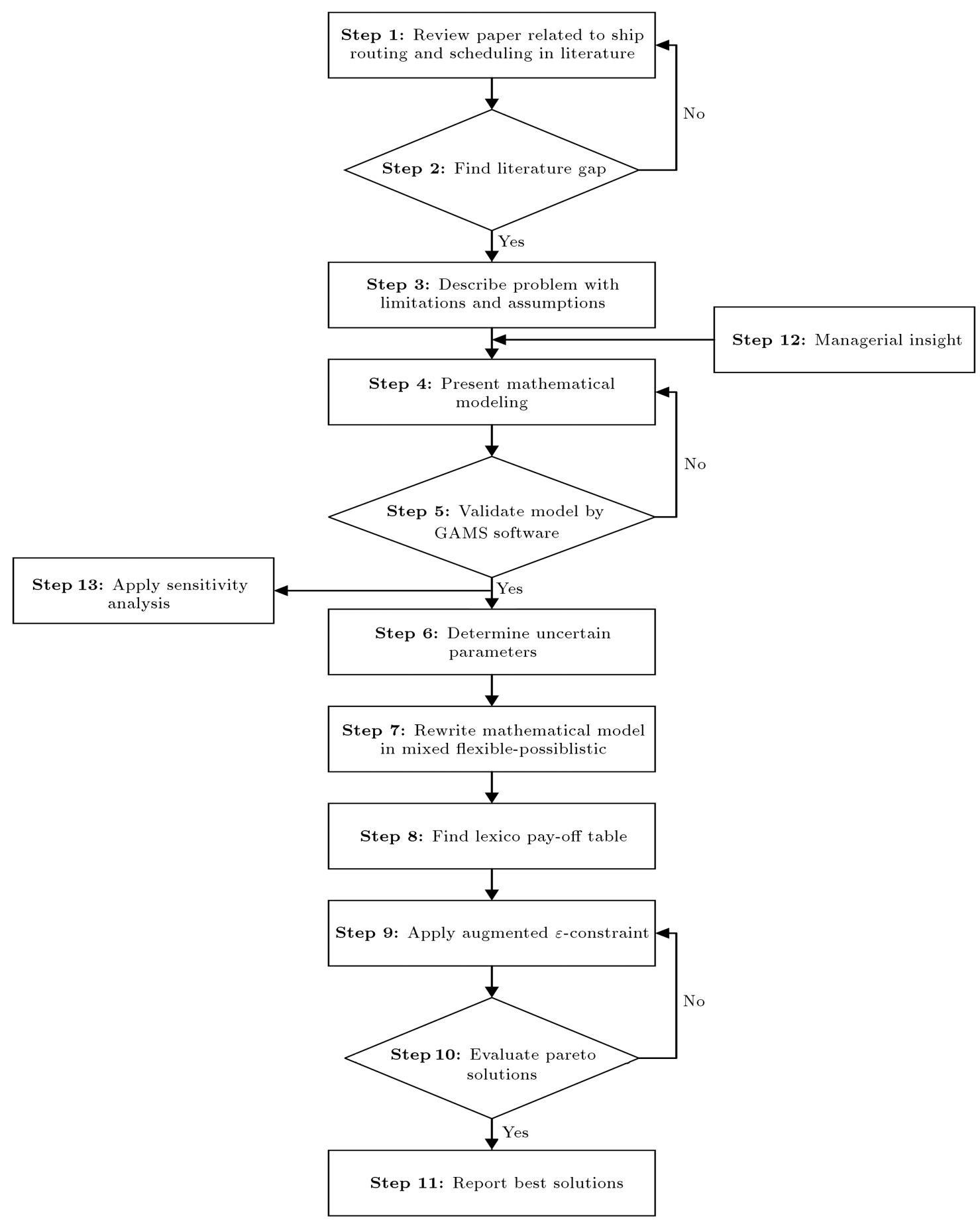

Figure 4. Methodology of the paper to find the best solutions.

must be explored in our Multi-Objective Problem (MOP). In popular methods, the Decision-Maker (DM) should determine the priority or weight of the objective functions before or after the solution process or interactively. It is important to choose a method capable of choosing efficient solutions rather than weak, inefficient solutions [50].

One of the most widely used methods to achieve efficient Pareto-optimal solutions in MOP is the $\varepsilon$ constraint method. In the $\varepsilon$-constraint method, DM should determine the most desirable Pareto solutions after the solution process (the posteriori method). Indeed, the Pareto-optimal solutions are determined by the $\varepsilon$-constraint method with different $\varepsilon$ values on the Right-Hand Side (RHS) of the objective functions considered as additional constraints, until the DM is 


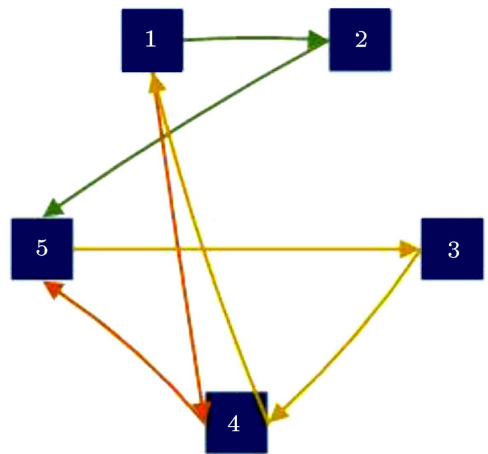

Figure 5. Optimal solution by considering cost objective function.

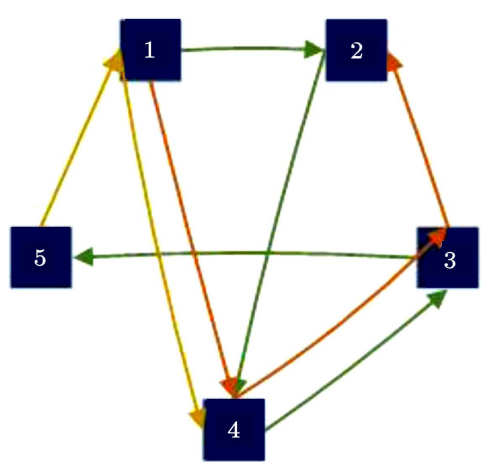

Figure 6. Optimal solution by considering the social objective function.

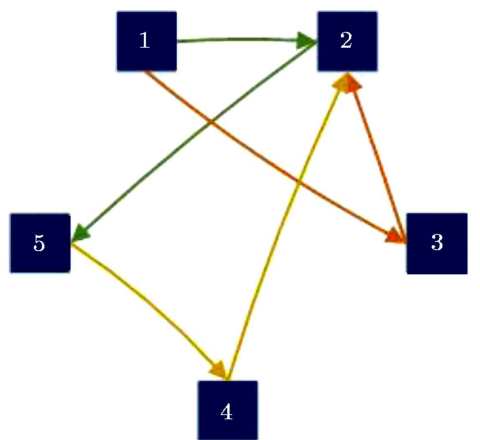

Figure 7. Optimal solution by considering the environmental objective function.

satisfied (effective implementation of the $\varepsilon$-constraint method in multi-objective mathematical programming problems). It is proved that the $\varepsilon$-constraint method explores efficient solutions; however, it may also generate infeasible solutions [51]. Therefore, the $\varepsilon$-constraint method is extended by an improved version of the augmented e-constraint method (AUGMECON2) to determine the exact Pareto set in multi-objective integer programming problems. In Augmented $\varepsilon$ constraint (AUGMECON) method, only the efficient solution is explored. To solve the ship-routing multiobjective optimization problem, a two-stage approach is proposed.

In the first stage, the uncertainty of parameters in the objective functions and constraints and flexibility of the constraint are recognized, and the crisp equivalent counterpart of the model formulation is provided by the mixed flexible-probabilistic approach, as mentioned earlier. In the second stage, lexicographic and augmented $\varepsilon$-constraint methods are applied to explore efficient Pareto-optimal solutions.

Consider the problem of minimizing $P$ conflicting objective functions. The AGMECON optimizes the main objective function (usually, the cost objective is considered as the main objective) through Eq. (27) subject to other objectives constrained through Eq. (28) and feasible decision space.

$$
\begin{aligned}
& \min \left\{f_{1}(x)-\left(r_{1} \times \sum_{i=2}^{p} \frac{s_{i}}{r_{i}}\right),\right. \\
& \text { subject to: } x \in X \wedge f_{i}(x)+s_{i}=\varepsilon_{i} \wedge s_{i} \in R^{+}, \\
& \qquad i=2, \cdots, p\},
\end{aligned}
$$

where $f_{1}(x)$ is the main objective, $f_{i}(x)$ is the $i$ th objective function, $x$ denotes the decision variable, $s_{i}$ denotes the $i$ th slack or surplus variable, and $r_{i}$ represents the range of the $i$ th objective function calculated from the pay-off table. The pay-off table is a square table of $p$ rows and columns to find the positive ideal solutions of the objective functions $\left(f^{P I S}\right)$ and negative ideal solutions of the objective functions $\left(f^{N I S}\right)$. Then, the range of each objective is calculated simply by Eq. (29):

$$
r_{i}=f_{i}^{N I S}-f_{i}^{P I S} .
$$

This study applies the lexicographic method as in Eqs. (30)-(38) to calculate $f^{P I S}$ and $f^{N I S}$ from the pay-off table:

$i \quad$ Model $(i=1,2, \cdots, p) \quad$ Optimum solution

$$
\begin{array}{llll}
i=1 & \text { minimization } & \min Z_{1} & \dot{Z}_{1}, \\
& \text { S.T. } \quad x \in X, & & \\
& \text { maximization } & \max Z_{2}, & \\
& \text { S.T. } \quad x \in X & & \dot{Z}_{2}, \\
& Z_{1}=\dot{Z}_{1}, & & \\
& & & \\
& \text { minimization } & \min Z_{3} & \dot{Z}_{3}, \\
& \text { S.T. } \quad x \in X, & & \\
& Z_{1}=\dot{Z}_{1},
\end{array}
$$




$$
Z_{2}=\dot{Z}_{2}
$$

Then, $\varepsilon$-vector can be calculated via Eq. (39) with $m$ grid points or $(m-1)$ equal intervals.

$$
\varepsilon_{i}=f_{i}^{N I S}-\left(\frac{f_{i}^{N I S}-f_{i}^{P I S}}{m}\right) \times n=0,1,2, \cdots, m .
$$

A high number of grid points generates solutions that are more efficient. The problem can be solved by different grid points to achieve more efficient solutions until the DM is satisfied. The proposed solution to the sustainable ship routing and scheduling problem is summarized as follows:

Step 1: Determine the uncertain parameters;

Step 2: Convert the model into a mixed flexibleprobabilistic equivalent;

Step 3: Apply the lexicographic method to build the payoff table;

Step 4: Calculate the range of each objective function according to the obtained payoff table from Step 3 by Eq. (29);

Step 5: Construct the $\varepsilon$-vectors according to the ranges obtained in Step 4 for each objective function;

Step 6: Use the augmented $\varepsilon$-constraint method to find efficient solutions from the Pareto-optimal set. If the DM is satisfied with the acquired efficient solutions, then stop; otherwise, go to Step 5 to find more efficient solutions.

\section{Numerical results}

In this section, the computational results of this paper are presented, in which the mathematical model is validated by applying several test problems, and the conflict between the three objectives of the model is checked. Then, sensitivity analysis is applied to different values of decision-makers' satisfaction degrees on both parameters of the solution method and proposed crisp equivalent counterpart of the model.

\subsection{Model validation}

In order to validate the proposed mathematical model, several random small examples are solved with GAMS software in a Core i5 ASUS laptop computer. Each objective is solved by GAMS software with model constraints separately to show the conflict of objectives. A range of parameters with their common module used to solve sample problems are in Table 3 . It should be noted that knots can be a common module for measuring the ship's speed $(1$ knots $=1.852 \mathrm{~km} / \mathrm{h})$. A uniform parameter is a number between its specific ranges with the same possibility for the occurrence of each number in the range. For example, it is common that ships can be available in small ship transportation Companies 1, 2 or 3 . In addition, the fuel cost of traveling $1 \mathrm{~km}$ by a ship at a speed of $1.85 \mathrm{~km} / \mathrm{h}$ is usually at least 130 and at most 170 .

\subsection{Objective conflict}

The proposed problem is defined by a multi-objective sustainable mathematical model. This model contains three dimensions of sustainability (i.e., economic, social, and environmental). The first objective is to minimize the cost of ship operation due to its optimal routing and scheduling. This objective contains ship fuel cost, ship travel taxes, cost of renting each ship, cost of hiring ship and port workers, and reward of transporting shipments. The second objective considers the social aspect of sustainability by maximizing job creations. The number of workers in ports and ships is considered to be maximized in the social dimension. The third objective concerns the minimization of $\mathrm{CO}_{2}$ while considering penalty cost or transporting hazardous shipments such as gas, oil, etc. Table 4 shows the conflict between cost and social objectives, since cost is a minimization objective and social dimension is a maximization one. It is demonstrated that, with an increase in unfavorable cost, job creation maximizes positively. Figures 5-7 show the optimum solution by

Table 4. Conflict between cost and social objectives.

\begin{tabular}{ccc}
\hline $\begin{array}{c}\text { Number } \\
\text { of worker }\end{array}$ & OFV1 (cost) & OFV2 (social) \\
\hline 13 & 853080 & 260 \\
14 & 853100 & 280 \\
15 & 853120 & 300 \\
16 & 853150 & 320 \\
17 & 853170 & 340 \\
\hline
\end{tabular}

Table 3. Range of parameters value of sample problems.

\begin{tabular}{llll}
\hline \multicolumn{1}{c}{ Parameters } & \multicolumn{1}{c}{ Values } & \multicolumn{1}{c}{ Parameters } & \multicolumn{1}{c}{ Values } \\
\hline$n_{s}$ & $\sim$ Uniform $(1,3)$ & {$\left[a_{i}, b_{i}\right]($ day $)$} & $\sim$ uniform $[(0,5),(10,20)]$ \\
$c_{s}^{v}($ dollar $/ \mathrm{km})$ & $\sim$ Uniform $(130,170)$ & Speeds $($ knots $)$ & Rnd $(10,12,14,16)$ \\
$g_{v}(\mathrm{~h} / \mathrm{km})$ & $\sim$ Uniform $(0.1,0.9)$ & $p_{i}$ & $\sim$ uniform $(1,3)$ \\
$f_{i s}$ & Binary & $w s_{s}$ & $\sim$ uniform $(12,14)$ \\
$b_{i}^{v}($ dollar $)$ & $\sim$ Uniform $(4500,7000)$ & $M_{s}($ dollar $)$ & 30 per day \\
$e_{i s}^{v}($ dollar $)$ & 4500 per day & $\mathrm{CO}_{2_{s v}}(\mathrm{~g})$ & $\sim$ uniform $(10,40)$ \\
$d_{i j}(\mathrm{~km})$ & $\sim$ Uniform $(20,300)$ & $h_{i}$ & 0 or $\sim$ uniform $(2500,5000)$ \\
\hline
\end{tabular}


considering the cost, social, and environmental objective functions. According to these figures, different results have been obtained regarding different objective functions. Therefore, there is a conflict between the three objective functions.

\subsection{Sensitivity analysis}

In this section, several test problems are solved with different values of the proposed parameters. Sensitivity analysis is applied to the parameters that affect the obtained routes and objective functions, significantly. The model is solved with a different number of workers. Figures 8 and 9 show the effect of the number of workers on cost and social objectives, respectively. According to test problems, (as we could predict it before) by increasing the number of workers, the social objective will possessively increase and cost objective will increase adversely. It is shown that there is an evident conflict between these objectives. As shown in Figure 10, the purpose of the paper is to find solutions for creating a balance between cost and social objectives.

Each ship serves the shipments at different speeds. The shipments are transported at a higher speed in a shorter time; however, the amount of $\mathrm{CO}_{2}$ emissions increases. Since higher speeds consume more

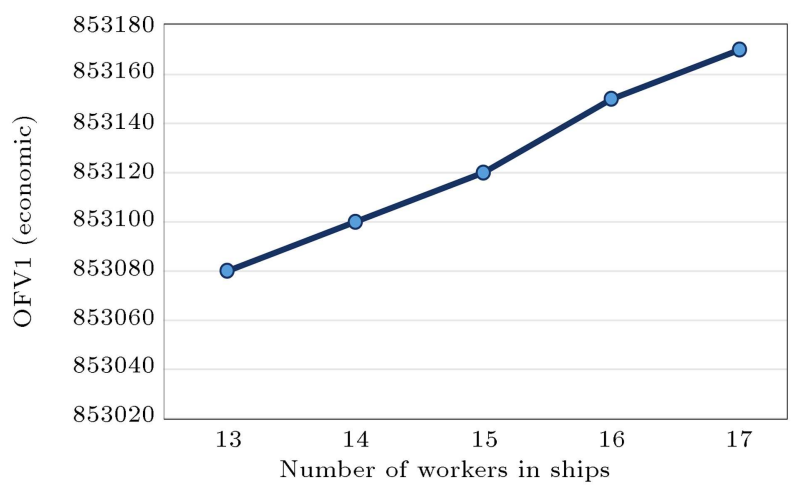

Figure 8. Cost objective function versus the number of workers.

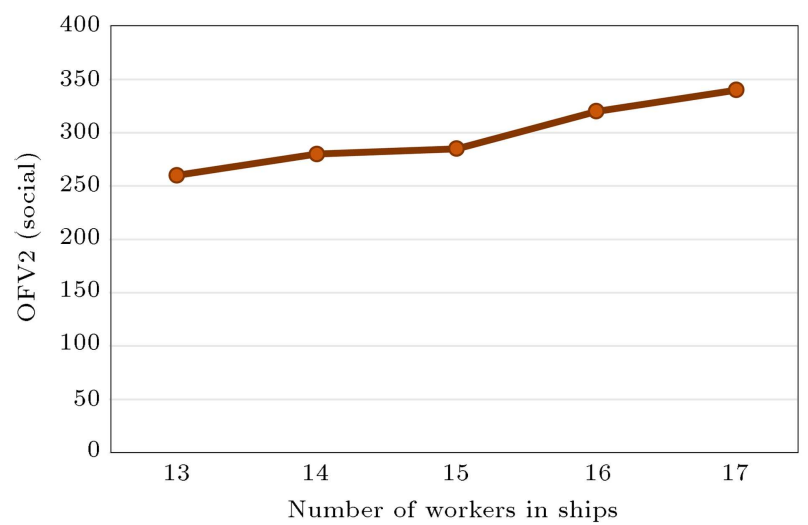

Figure 9. Social objective function versus the number of workers. fuel, transportation with higher speeds is costlier (see Figure 11). Environmental objective function changes with an increase in $\mathrm{CO}_{2}$ emissions, as shown in Figure 12. Test problems are solved with the proposed solution method. Table 5 shows the pay-off table for the objective functions. Moreover, different Pareto-

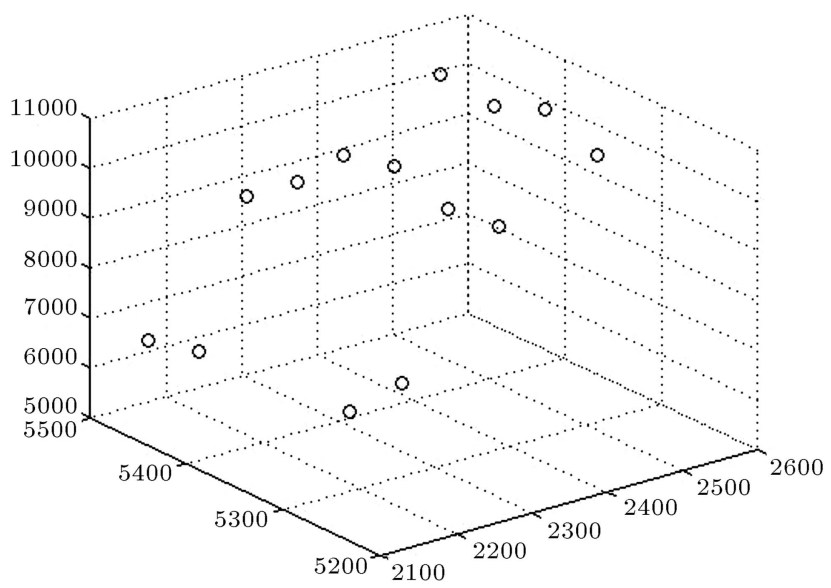

Figure 10. Obtained Pareto solutions for the problem.

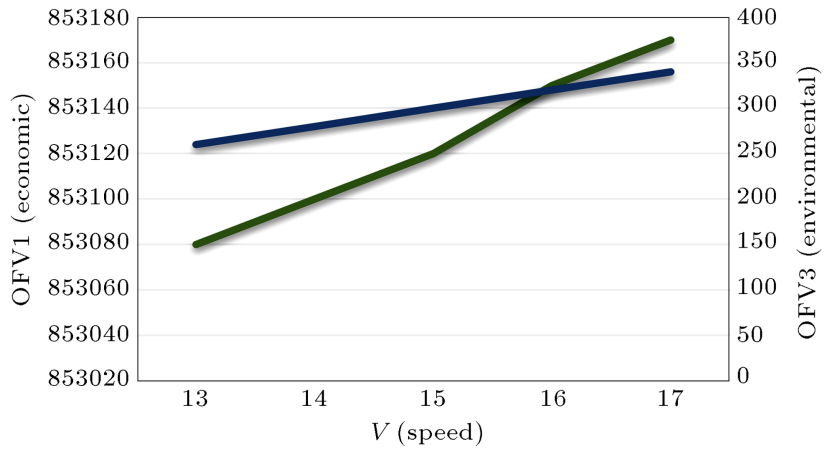

Figure 11. Cost and environmental objective functions versus the different speed.

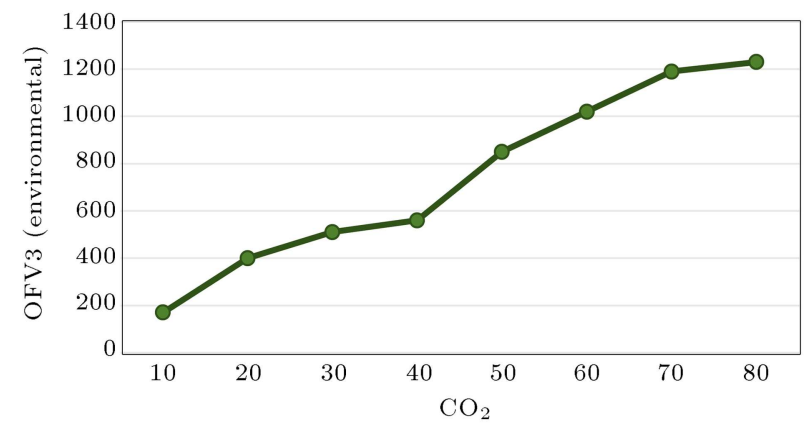

Figure 12. Environmental objective function versus $\mathrm{CO}_{2}$ emissions.

Table 5. Payoff table for three objectives of sample problems.

\begin{tabular}{lccc}
\hline & $\boldsymbol{Z}_{\mathbf{1}}$ & $\boldsymbol{Z}_{\mathbf{2}}$ & $\boldsymbol{Z}_{\mathbf{3}}$ \\
\hline $\operatorname{Min} \boldsymbol{Z}_{\mathbf{1}}$ & $934000^{*}$ & 250 & 180 \\
$\operatorname{Max} \boldsymbol{Z}_{\mathbf{2}}$ & 1660000 & $310^{*}$ & 155 \\
$\operatorname{Min} \boldsymbol{Z}_{\mathbf{3}}$ & 87400 & 100 & $160^{*}$ \\
\hline
\end{tabular}


Table 6. Value of different speed levels versus $\mathrm{CO}_{2}$ emission versus fuel consumption.

\begin{tabular}{ccc}
\hline $\begin{array}{c}\text { Speed } \\
(\text { knots })\end{array}$ & $\begin{array}{c}\mathbf{C O}_{2} \text { emission } \\
(\mathrm{g})\end{array}$ & $\begin{array}{c}\text { Fuel consumption } \\
(\mathbf{t})\end{array}$ \\
\hline 10 & 10 & 12 \\
12 & 20 & 25 \\
14 & 30 & 38 \\
16 & 40 & 51 \\
\hline
\end{tabular}

optimal solutions to the test problem are shown in Figure 10. Different values of speed, $\mathrm{CO}_{2}$ emission, and fuel consumption, which are used to solve test problems and our case-study problem, are shown in Table 6 .

\section{Case study}

A company with some activities associated with maritime transportation has been selected as a real case study in this paper. This company is a large oil company located in Iran and has several departments in different fields related to the oil industry. Its logistic department regularly services some oil platforms that are located in the Persian Gulf. These services are provided with average twelve Anchor Handling Tug Supply (AHTS) ships, which are usually rented by the considered company. Although AHTS can travel with four different speed levels (10, 12, 14, and 16 knots), ships of this company only travel with a minimum speed (10 knots). All ships are of the same kind and have a certain capacity. Moreover, this problem is a full-shipload shipping. There are ten major nodes for this company's shipping problem including five oil platforms in the Persian Gulf; five of Iran's ports are located in the south of Iran and one of United Arab Emirate major port is named Sharjah. A schematic view of these nodes along with their detailed names is shown in Figure 13 and Table 7.

The number of laborers working in each ship is between 12 and 14. All other related information used as inputs in this paper includes fuel cost of full and empty ships, transit time, distance between nodes, and ships' technical specifications such as variable speeds and $\mathrm{CO}_{2}$ emission used from case study database.

\subsection{Case study computational result}

In this section, the performance of AUGMENTED epsilon constraint method is evaluated by the proposed ship routing and scheduling model. The problem of a maritime transportation company is modeled to show the applicability of the proposed model in real situations.

To solve the proposed model, real data from the stated company are used; 5 oil platforms, 5 ports, and 12 ships with four-speed levels $(10,12,14$, and 16 knots) are considered. Each port has a time

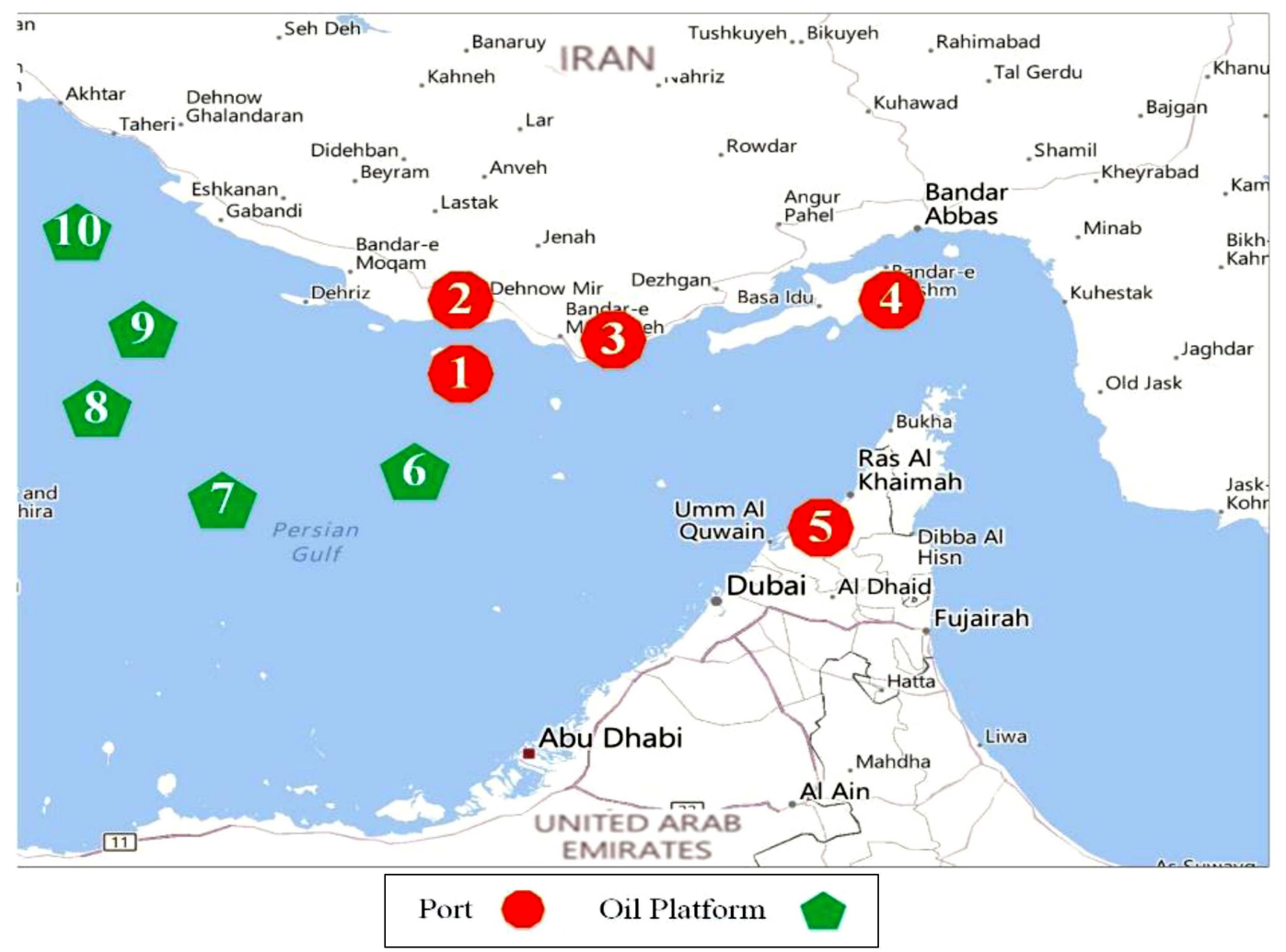

Figure 13. A schematic form of the case-study ports and platforms in the map. 
Table 7. Case study nodes' names.

\begin{tabular}{cccc}
\hline Ports number & Name & Platforms number & Name \\
\hline 1 & Kish Island, Iran & 6 & Oil platform A \\
2 & Bandar Charak, Iran & 7 & Oil platform B \\
3 & Bandar Lengeh, Iran & 8 & Oil platform C \\
4 & Qeshm Island, Iran & 9 & Oil platform D \\
5 & Sharjah, United Arab Emirates & 10 & Oil platform F \\
\hline
\end{tabular}

Table 8. Results of the case study.

\begin{tabular}{clccc}
\hline $\begin{array}{c}\text { Ship } \\
\text { number }\end{array}$ & \multicolumn{1}{c}{ Route } & $\begin{array}{c}\text { Served } \\
\text { ports }\end{array}$ & $\begin{array}{c}\text { Travel } \\
\text { time }\end{array}$ & $\begin{array}{c}\mathbf{C O}_{2} \\
\text { emission }\end{array}$ \\
\hline S1 & $2 \rightarrow 10 \rightarrow 8 \rightarrow 1$ & $10-8$ & 33 & 396 \\
S2 & $1 \rightarrow 7 \rightarrow 9 \rightarrow 2$ & $7-9$ & 34 & 408 \\
S3 & $2 \rightarrow 9 \rightarrow 7 \rightarrow 3$ & $2-9-7$ & 34 & 408 \\
S4 & $2 \rightarrow 10 \rightarrow 3$ & $2-10$ & 30 & 360 \\
S5 & $5 \rightarrow 3$ & 9 & 12 & 144 \\
S6 & $5 \rightarrow 6 \rightarrow 8 \rightarrow 7 \rightarrow 4$ & $8-7$ & 39 & 468 \\
S7 & $1 \rightarrow 2 \rightarrow 9 \rightarrow 6 \rightarrow 3$ & $2-9-6$ & 38 & 456 \\
S8 & $5 \rightarrow 8 \rightarrow 4$ & 8 & 49 & 588 \\
S9 & $4 \rightarrow 8 \rightarrow 5$ & 8 & 53 & 636 \\
S10 & $1 \rightarrow 9 \rightarrow 2 \rightarrow 7 \rightarrow 3$ & $9-2-7$ & 33 & 396 \\
S11 & $5 \rightarrow 2$ & 7 & 14 & 168 \\
S12 & $4 \rightarrow 5$ & 8 & 28 & 336 \\
\hline
\end{tabular}

window in which the shipment should start being loaded. Sustainable problem considers three objectives simultaneously. The problem is aimed at minimizing total costs, maximizing the social effect by maximizing job opportunity, minimizing total environmental damages caused by $\mathrm{CO}_{2}$ emissions from ships, and decreasing utility of serving hazardous materials such as oil and gas. Uncertainty is considered for some of the model's parameters in order to deal with the lack of data and changing of some parameters in different time periods. The mixed flexible-probabilistic method is used to convert the model with uncertain parameters to its crisp equivalent. The mathematical model is solved by the augmented epsilon constraint method. Results of ships routing and scheduling are shown in Table 8. Numbers 1 to 12 are assigned to each ship with its name; time windows show the start time of ships' travels (time unit is the day); routes in each time window are available in Table 8 . The longest ship travel ends by 3 routes at 31 days.

\subsection{Managerial insights into the case study}

In this section, the proposed mathematical model is extended in order to achieve managerial insights. Accordingly, $n_{s}$ is considered as a variable that determines the number of ships. Notably, in the stated case, there are a predetermined number of ships. However, this model suggests that the stated company hire the optimum number of ships. In the following model, we are going to determine the optimum number of available ships:

$$
\begin{array}{ll}
\min & \sum_{s \in S} \sum_{v \in V} h_{s}^{v} n_{s}, \\
\max & \sum_{s \in S} n_{s}, \\
\min & \sum_{s \in S} \sum_{v \in V} \mathrm{CO}_{2_{s v}} n_{s},
\end{array}
$$

Subject to:

$$
\begin{aligned}
& \min _{s} \leq n_{s} \leq \max _{s} \quad \forall v \in V, \quad s \in S, \\
& n_{s, v} \geq 0, \text { integer } \quad \forall v \in V, \quad s \in S,
\end{aligned}
$$

where $\min _{s}$ is the minimum number of ships whose decision-maker thinks are necessary (can be zero), $\max _{s}$ is the maximum number of ships which the company can afford to rent each year due to company capital, and $h_{s}^{v}$ indicates the hiring cost of ship $s$ with speed $v$. The first objective minimizes the hiring cost of ships, and the second objective maximizes the number of available ships (it maximizes the social effect by hiring more workers). The third objective minimizes the total $\mathrm{CO}_{2}$ produced by ships. Results of resolving the model by adding the objectives to their corresponding, i.e., Eqs. (1)-(3) and Eqs. (43) and (44), are shown in Table 9 . It is important to note that these equations, which are constant, are added to the first model; hence, we did not consider them in the model.

\section{Conclusion}

In this study, a fuzzy multi-objective ship routing and scheduling problem was presented to satisfy three sustainable objectives. The proposed problem was aimed at finding the best route and schedule for each ship while minimizing cost and $\mathrm{CO}_{2}$ emission and maximizing the job creation at the same time. Variable 
Table 9. Different results by considering the number of ships as a parameter and the number of ships as a variable.

\begin{tabular}{ccccccccc}
\hline \multirow{2}{*}{$\begin{array}{c}\text { Pareto } \\
\text { iteration }\end{array}$} & \multicolumn{3}{c}{$\begin{array}{c}\text { Number of ships } \\
\text { as a parameter }\end{array}$} & & \multicolumn{3}{c}{$\begin{array}{c}\text { Number of ships } \\
\text { as variable }\end{array}$} \\
\cline { 2 - 3 } & $\boldsymbol{n}$ & OFV1 & OFV2 & & $\boldsymbol{n}$ & OFV1 & OFV2 \\
\hline 1 & 12 & 35660 & 1782 & & 13 & 38743 & 2234 \\
2 & 12 & 34454 & 1824 & & 13 & 38743 & 2104 \\
3 & 12 & 50675 & 1657 & & 13 & 38743 & 2253 \\
4 & 12 & 29875 & 1755 & & 12 & 35730 & 1845 \\
5 & 12 & 38368 & 1647 & & 12 & 35746 & 1832 \\
6 & 12 & 32567 & 1501 & & 12 & 43854 & 1794 \\
7 & 12 & 53435 & 1657 & & 12 & 34616 & 1573 \\
8 & 12 & 49278 & 1747 & & 12 & 36748 & 2623 \\
9 & 12 & 45473 & 1583 & & 12 & 48842 & 3375 \\
10 & 12 & 43536 & 1784 & & 13 & 37845 & 1753 \\
11 & 12 & 32478 & 1582 & & 13 & 38654 & 1738 \\
12 & 12 & 31245 & 1584 & & 13 & 46776 & 1843 \\
\hline
\end{tabular}

speed levels were considered to find the optimal speed for each ship considering the correlation of speed with ship's emission and fuel consumption. Uncertainty was added to the model by converting it to the mixed flexible-probabilistic robust programming. Several test problems were conducted in order to validate the mathematical model by GAMS software, and effects of different parameters on objectives were evaluated by applying sensitivity analysis. The augmented $\varepsilon-$ constraint was used as a solution methodology to solve the proposed problem. In addition, real input data were considered from a case study to solve the model in large-sized problems. The proposed mathematical model was extended to achieve the optimal number of ships and an optimum speed for each ships. Computational results showed the considerable positive influence (about $13 \%$ ) of this study's contributions. Maritime transportation managers and decision-makers can use the numerical results, sensitivity analyses, and managerial insights in their decisions obtained in this paper. Moreover, considering different kinds of maritime risk in routes and considering variable speeds in the continuous form is a possible extent to this paper.

\section{References}

1. Agarwal, R. and Ergun, O. "Ship scheduling and network design for cargo routing in liner shipping", Transportation Science, 42(2), pp. 175-196 (2008).

2. UNCTAD. "Review of maritime transport", United Nations Conference on Trade and Development, New York and Geneva, United Nation (2013).

3. Lawrence, S.A., International Sea Transport: The Years Ahead, Lexington Books (1972).

4. Christiansen, M. and Nygreen, B. "Robust inventory ship routing by column generation", In Column Generation, pp. 197-224. Springer, Boston, MA (2005).

5. Buhaug, Ø., Corbett, J.J., Endresen, Ø., Eyring, V., Faber, J., Hanayama, S., Lee, D.S., et al. "Second imo ghg study", International Maritime Organization (IMO), London, UK 24 (2009).

6. Ryder, S.C. and Chappel, D., Optimal Speed and Ship Size for the Liner Trades, University of Liverpool, Marine Transport Centre (1979).

7. Ronen, D. "The effect of oil price on the optimal speed of ships", Journal of the Operational Research Society, 33(11), pp. 1035-1040 (1982).

8. Wen, M., Ropke, S., Petersen, H.L., Larsen, R., and Madsen, O.B. "Full-shipload tramp ship routing and scheduling with variable speeds", Computers \& Operations Research, 70, pp. 1-8 (2017).

9. De, A., Mamanduru, V.K.R., Gunasekaran, A., Subramanian, N., and Tiwari, M.K. "Composite particle algorithm for sustainable integrated dynamic ship routing and scheduling optimization", Computers \& Industrial Engineering, 96, pp. 201-215 (2016).

10. Jansen, L. "The challenge of sustainable development", Journal of Cleaner Production, 11(3), pp. 231245 (2003).

11. Vachon, S. and Mao, Z. "Linking supply chain strength to sustainable development: a country-level analysis", Journal of Cleaner Production, 16(15), pp. 1552-1560 (2008).

12. Čuček, L., Klemeš, J.J., and Kravanja, Z. "A review of footprint analysis tools for monitoring impacts on sustainability", Journal of Cleaner Production, 34, pp. 9-20 (2012).

13. Ronen, D. "Cargo ships routing and scheduling: Survey of models and problems", European Journal of Operational Research, 12(2), pp. 119-126 (1999).

14. Ronen, D. "Marine inventory routing: Shipments planning", Journal of the Operational Research Society, 53(1), pp. 108-114 (2002).

15. Psaraftis, H.N. "Ship routing and scheduling: the cart before the horse conjecture", Maritime Economics \& Logistics, 21(1), pp. 1-14 (2017).

16. Brønmo, G., Christiansen, M., and Nygreen, B. "Ship routing and scheduling with flexible cargo sizes", Journal of the Operational Research Society, 58(9), pp. 1167-1177 (2007).

17. Christiansen, M. "Decomposition of a combined inventory and time constrained ship routing problem", Transportation Science, 33(1), pp. 3-16 (1999).

18. Ting, S.C. and Tzeng, G.H. "Ship scheduling and cost analysis for route planning in liner shipping", Maritime Economics \& Logistics, 5(4), pp. 378-392 (2003).

19. Bendall, H.B. and Stent, A.F. "A scheduling model for a high speed containership service: A hub and spoke short-sea application", International Journal of Maritime Economics, 3(3), pp. 262-277 (2001). 
20. Azaron, A. and Kianfar, F. "Dynamic shortest path in stochastic dynamic networks: Ship routing problem", European Journal of Operational Research, 144(1), pp. 138-156 (2003).

21. Hwang, S.J. "Inventory constrained maritime routing and scheduling for multi-commodity liquid bulk", $\mathrm{PhD}$ dissertation, Georgia Institute of Technology (2005).

22. Korsvik, J.E., Kjetil Fagerholt, K., and Laporte, G. "A large neighbourhood search heuristic for ship routing and scheduling with split loads", Computers \& Operations Research, 38(2), pp. 474-483 (2011).

23. Fagerholt, K., Christiansen, M., Hvattum, L.M., Johnsen, T.A., and Vabø., T.J. "A decision support methodology for strategic planning in maritime transportation", Omega, 38(6), pp. 465-474 (2010a).

24. Stålhane, M., Andersson, H., Christiansen, M., Cordeau, J.F., and Desaulniers, G. "A branch-priceand-cut method for a ship routing and scheduling problem with split loads", Computers \& Operations Research, 39(12), pp. 3361-3375 (2012).

25. Agra, A., Christiansen, M., and Delgado, A. "Mixed integer formulations for a short sea fuel oil distribution problem", Transportation Science, 47(1), pp. 108-124 (2013).

26. Moon, I.K., Qiu, Z.B. and Wang, J.H. "A combined tramp ship routing, fleet deployment, and network design problem", Maritime Policy \& Management, 42(1), pp. 68-91 (2015).

27. Corbett, J.J. and Koehler, H.W. "Updated emissions from ocean shipping", Journal of Geophysical Research: Atmospheres., 108(D20) (2003).

28. Corbett, J.J., Haifeng Wang, and Winebrake, J.J. "The effectiveness and costs of speed reductions on emissions from international shipping", Transportation Research Part D: Transport and Environment, 14(8), pp.593-598 (2009).

29. Ronen, D. "The effect of oil price on containership speed and fleet size", Journal of the Operational Research Society, 62(1), pp. 211-216 (2011).

30. Eyring, V., Köhler, H.W., Van Aardenne, J., and Lauer, A. "Emissions from international shipping: 1. The last 50 years", Journal of Geophysical Research: Atmospheres, 110, D17 (2005).

31. Endresen, Ø., Sørgård, E., Behrens, H.L., Brett, P.O., and Isaksen, I.S. "A historical reconstruction of ships' fuel consumption and emissions", Journal of Geophysical Research: Atmospheres, 112, D12 (2007).

32. Yin, J., Fan, L. Yang, Z., and Li, K.X. "Slow steaming of liner trade: its economic and environmental impacts", Maritime Policy \& Management, 41(2), pp. 149-158 (2014).

33. McKinnon, A. "The possible influence of the shipper on carbon emissions from deep-sea container supply chains: An empirical analysis", Maritime Economics \& Logistics, 16(1), pp. 1-19 (2014).
34. Norstad, I., Fagerholt, K., and Laporte, G. "Tramp ship routing and scheduling with speed optimization", Transportation Research Part C: Emerging Technologies, 19(5), pp. 853-865 (2011).

35. Gatica, R.A. and Miranda, P.A. "Special issue on Latin-american research: a time based discretization approach for ship routing and scheduling with variable speed", Networks and Spatial Economics, 11(3), pp. 465-485 (2011).

36. Wang, S. and Meng, Q. "Sailing speed optimization for container ships in a liner shipping network", Transportation Research Part E: Logistics and Transportation Review, 48(3), pp. 701-714 (2012).

37. Psaraftis, H.N. and Christos A. Kontovas "Ship speed optimization: Concepts, models and combined speedrouting scenarios", Transportation Research Part C: Emerging Technologies, 44, pp. 52-69 (2014).

38. Andersson, H., Fagerholt, K., and Hobbesland, K. "Integrated maritime fleet deployment and speed optimization: Case study from RoRo shipping", Computers \& Operations Research, 55(5), pp. 233-240 (2015).

39. Dubois, D., Fargier, H., and Fortemps, Ph. "Fuzzy scheduling: Modelling flexible constraints vs. coping with incomplete knowledge", European Journal of Operational Research, 147(2), pp. 231-252 (2003).

40. Bellman, R.E. and Zadeh, L.A. "Decision-making in a fuzzy environment", Management Science, 17(4), B141 (1970).

41. Mula, J., Poler, R., and Garcia, J.P. "MRP with flexible constraints: A fuzzy mathematical programming approach", Fuzzy Sets and Systems, 157(1), pp. 74-97 (2007).

42. Pishvaee, M.S. and Torabi, S.A. "A possibilistic programming approach for closed-loop supply chain network design under uncertainty", Fuzzy sets and Systems, 161(20), pp. 2668-2683 (2010).

43. Celik, M., Cebi, S., Kahraman, C., and Er, I.D. "Application of axiomatic design and TOPSIS methodologies under fuzzy environment for proposing competitive strategies on Turkish container ports in maritime transportation network", Expert Systems with Applications, 36(3), pp. 4541-4557 (2009).

44. Christiansen, M. and Fagerholt, K. "Robust ship scheduling with multiple time windows", Naval Research Logistics (NRL), 49(6), pp. 611-625 (2002).

45. Christiansen, M., Fagerholt, K., and Ronen, D. "Ship routing and scheduling: Status and perspectives", Transportation Science, 38(1), pp. 1-18 (2004).

46. Pishvaee, M.S. and Fazli Khalaf, M.R. "Novel robust fuzzy mathematical programming methods", Applied Mathematical Modelling, 40(1), pp. 407-418 (2016).

47. Chuang, T.N., Lin, C.T., Kung, J.Y., and Lin, M.D. "Planning the route of container ships: A fuzzy genetic approach", Expert Systems with Applications, 37(4), pp. 2948-2956 (2010). 
48. Fagerholt, Kjetil, Laporte, G., and Inge Norstad "Reducing fuel emissions by optimizing speed on shipping routes", Journal of the Operational Research Society, 61(3), pp. 523-529 (2010).

49. Pishvaee, M.S., Razmi, J., and Torabi, S.A. "Robust possibilistic programming for socially responsible supply chain network design: A new approach", Fuzzy Sets and Systems, 206, pp. 1-20 (2012).

50. Greco, S., Figueira, J., and Ehrgott, M., Multiple Criteria Decision Analysis, Springer's International Series (2005).

51. Mavrotas, G. "Effective implementation of the $\varepsilon$ constraint method in multi-objective mathematical programming problems", Applied mathematics and Computation, 213(2), pp. 455-465 (2009).

\section{Biographies}

Masoud Rabbani is a Professor of Industrial Engineering in the School of Industrial and Systems Engineering at University of Tehran. He has published more than 80 papers in international journals, such as European Journal of Operational Research, International Journal of Production Research, and International Journal of Production Economics, among others. His research interests include productionplanning, design of inventory management systems, applied graph theory in industrial planning, and productivity management.

Shohre Sadeghsa finished her Pre-university education in 11 years; then, she finished her Bachelor of Science in Industrial Engineering from University of Tehran, Iran in 2016. She continued her Master's studies at University of Tehran in Optimization field. She joined the double degree program between University of Tehran, Iran and Ecole Nationale Supérieure d'Arts et
Métiersm, France for the rest of her Master's studies. She has worked on nearly 10 conference and journal papers in her first year of Master's studies. She joined as a Research Assistant to Professor Iranmanesh's research team who is a Professor of the School of Industrial Engineering at University of Tehran. Her interests include blood and pharmacy supply chain, quality management, transportation (maritime transportation and public transportation), resiliency, and optimization algorithms.

Maliheh Vaez Alaei finished her Bachelor of Science in Industrial Engineering from Azad University South Tehran Branch, Iran in 2014. She is continuing her Master's studies at University of Tehran in Optimization field, Iran 2016-2017. She joined the double-degree program between University of Tehran, Iran and Ecole Nationale Supérieure d'Arts et Métiersm, France for the rest of her Master's studies. She has worked on nearly 6 conference and journal papers in her first year of Master's studies. Her interests include maritime transportation, routing and scheduling, sustainability, resiliency, and optimization algorithms.

Hamed Farrokhi-Asl finished his Bachelor of Science in Industrial Engineering from University of KhajeNasir University of Technology, Iran in 2013. He continued his Master's studies at University of Tehran and graduated in 2014. He has published nearly 60 conference and journal papers. He joined as a Research Assistant to Professor Rabbani's research team who is a Professor of the School of Industrial Engineering at University of Tehran. He started his PhD at Iran University of Science \& Technology and has recently started working on a new nature-inspired algorithm. His interests include waste management, green supply chain, and optimization algorithms. 